Turner et al.: Distribution, Morphology, Survival, and Genetics of Aspen (Populu

\title{
Distribution, MORPHOlOGy, SuRVIVAL, AND GENETICS OF ASPEN (Populus tremuloides) SEEDLINGS FOLLOWING THE 1988 YELLOWSTONE FIRES
}

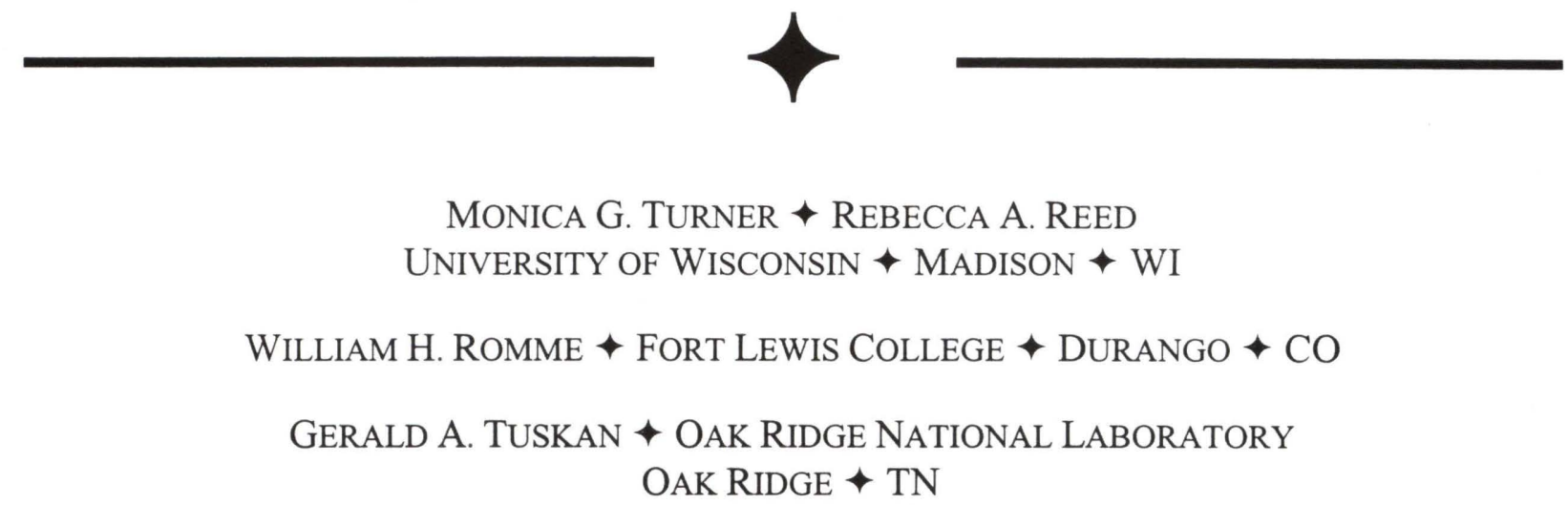

\section{$\downarrow \quad$ INTRODUCTION}

An unexpected consequence of the 1988 Yellowstone fires was the widespread establishment of seedlings of quaking aspen (Populus tremuloides) in the burned forests, including areas outside the previous range of aspen (Kay 1993, Romme et al. 1997). Although aspen is the most widely distributed tree species in North America (Fowells 1965), it is relatively uncommon and localized in distribution within Yellowstone National Park (Despain 1991). Most aspen stands in Yellowstone are found in the lower elevation landscapes in the northern portion of the park, and the species was absent -- prior to 1988 - across most of the high plateaus that dominate the southern and central park area. Aspen in the Rocky Mountain region reproduces primarily by means of vegetative root sprouting. Although viable seeds are regularly produced, establishment of seedlings in the wild is apparently a rare event due to the limited tolerance of aspen seedlings for desiccation or competition (e.g., Pearson 1914, McDonough 1985). In the immediate aftermath of the 1988 Yellowstone fires, there was a brief "window of opportunity" for aspen seedling establishment, as a result of abundant aspen seed production, moist weather conditions in spring and summer, and bare mineral soil and reduced plant competition within extensive burned areas (Jelinski and Cheliak 1992, Romme et al. 1997).

We initiated this 3-year study in 1996 to address four questions about the aspen seedlings now growing in burned areas across the Yellowstone Plateau: (1) What are the broad-scale patterns of distribution and abundance of aspen seedlings across the subalpine plateaus of Yellowstone National Park? (2) What is the morphology and population structure -- e.g., proportions of genets (genetic individuals that developed from a single seed) and ramets (vegetative root sprouts produced by a genet) of various ages -- in aspen seedling populations? (3) What are the mechanisms leading to eventual persistence or extirpation of seedling populations along an elevational gradient, particularly with respect to ungulate browsing and plant competition? (4) What is the genetic diversity and relatedness of the seedling populations along gradients of elevation and substrate? We completed our sampling for questions 2 and 4 in 1996 (see our 1996 annual report for details). In 1997 and again in 1998 we continued our annual sampling related to questions 1 and 3 . 


\section{METHODS}

We addressed the first question (broad-scale patterns of distribution and abundance) by counting aspen seedlings within belt transects along 18 trails distributed throughout the burned portions of the subalpine plateaus within Yellowstone National Park. We also established small permanent plots ca 20 meters off the trail every few kilometers, and measured aspen seedling density, height, and basal diameter within these plots (see our 1996 annual report for details). In 1997 and again in 1998 we resampled all of the trails and re-measured the seedlings in all of the permanent plots located along the trails.

We used an experimental approach to investigate mechanisms of persistence or extirpation of aspen seedlings (question \#3). At each of three different locations within burned forests, we fenced 13 small plots (approximately $100-500 \mathrm{~m}^{2}$ ) to exclude ungulates, and mapped 12 - 24 aspen seedlings for which we measured plant height, basal diameter, age, and number of leaves in late August, 1996. Experimental treatments at each of the three locations included: clipping of aspen plants to simulate elk browsing, removal of lodgepole pine and herbaceous plants within 1 meter of the measured aspen plants, clipping plus removal of competitors, and no clipping or competitor removal (see our 1996 annual report for details). In 1997 and again in 1998 we re-sampled all of the aspen seedlings within the exclosures, and made repairs on the exclosures as needed. We also constructed three new exclosures at our Fern Cascades site in 1997, and applied nitrogen fertilizer to the aspen seedlings growing inside as a new experimental treatment. Fertilizer was applied in late summer, 1997, and in early and late summer, 1998.

\section{$\uparrow \quad$ RESULTS}

Our annual report for 1996 presents results of our analysis of landscape-scale distribution and abundance in 1996. The primary purpose of resampling in 1997 and 1998 was to detect patterns of mortality (significant decreases in abundance) or persistence within different portions of the Yellowstone landscape. Comparison of 1996 through 1998 data is not yet complete. We noted qualitatively that in 1998 aspen seedlings were still present in all of the general areas where we found them in 1996. However, density of aspen plants within the permanent plots located along the trails decreased significantly between 1996 and 1998. We also observed that ungulate browsing continues to be heavy in all areas, and that nearly all of the aspen plants that germinated after 1988 are still $<1 \mathrm{~m}$ in height. These findings suggest that ungulate browsing may eventually eliminate most of the new aspen genets that established after 1988 .

Analysis of the data collected from our exclosure plots is not yet complete. Initial analyses indicate that simulated browsing (removal of all leaves and branches produced in the current year) led to significant reductions in plant height, diameter, and leaf number. However, even the plants that were protected from natural or simulated browsing generally grew only a few centimeters from 1996 1998. Thus, in addition to browsing effects, a mix of climatic, edaphic, and/or genetic factors appears to be limiting the height growth of the new aspen genets that established after the 1988 fires. A few individuals within the control exclosures at the lowest elevation site have grown $>1 \mathrm{~m}$ tall, and may eventually grow to tree size, but these individuals are exceptional.

\section{DISCUSSION}

We have taken advantage of a rare "natural experiment" -- the 1988 Yellowstone fires -- to investigate the responses of plant populations to large, infrequent disturbances. The results of this study may provide insights into likely effects on wildland ecosystems of other kinds of stresses and disturbances in the future, e.g., global climate change or altered fire regimes (Graham et al. 1990, Romme and Turner 1991). For long-lived, clonal plant species like aspen, either vegetative reproduction via root sprouting or sexual reproduction via seedling establishment may be effective for local reestablishment after disturbance. However, only seedling establishment is effective for long-distance dispersal and for broad-scale shifts in distribution of the species (Eriksson 1992) -- as may be necessary in the face of future climate change or habitat alteration in the northern Rocky Mountain region.

Two key questions remain unanswered: (1) Will the new aspen genets that established on the subalpine plateaus after the 1988 fires persist and effectively expand the range of aspen beyond what it was before 1988 ? Or will they succumb to ungulate browsing, competition from developing new stands of 
lodgepole pine, climatic constraints, or a combination of these factors, and gradually disappear from the Yellowstone landscape with no long-lasting ecological effects? (2) Where did the seeds come from that germinated to produce the aspen seedlings now growing outside the pre-1988 range of the species? Do the parents have a tree-like morphology or are they shrubs? Do the seedlings and their parents represent a broad spectrum of genetic diversity, or a limited sample of genotypes? Will genetic makeup be an important predictor of the ultimate survival or extinction of individual aspen seedlings across the Yellowstone landscape?

It may be many years before we have final answers to these questions. We plan to re-sample all of the trails, permanent trailside plots, and exclosure plots in about 3 years, and probably for several years thereafter. The long-term experimental plot studies and the genetic studies that we initiated in 1996 will help us understand the structure and dynamics of the aspen seedling populations, as well as the ecological mechanisms (e.g., ungulate browsing and plant competition) that will determine their eventual roles in the Yellowstone landscape.

\section{ACKNOWLEDGMENTS}

We thank our 1998 summer field crew for their hard work and diligence. This research was funded by the U. S. Department of Agriculture, National Research Initiative Competitive Grants Program, Forest/Range/Crop/Aquatic Ecosystems Program (Grant No. 95-37101-1689). Housing and logistical support were provided by the University of Wyoming - National Park Service Research Center. The Yellowstone Center for Resources and the Yellowstone Ranger Division furnished assistance throughout the field season.

\section{$\downarrow$ Literature Cited}

Despain, D. G. 1991. Yellowstone vegetation. Consequences of environment and history in a natural setting. Roberts Rinehart Publishers, Boulder, CO

Eriksson, O. 1992. Evolution of seed dispersal and recruitment in clonal plants. Oikos 63:439448.
Fowells, H.A. 1965. Silvics of forest trees of the United States. USDA Agricultural Handbook Number 271, Washington, D.C.

Graham, R. L. 1990. How increasing atmospheric $\mathrm{CO} 2$ and climate change affects forests. BioScience 40:575-587.

Jelinski, D. E., and W. M. Cheliak. 1992. Genetic diversity and spatial subdivision of Populus tremuloides (Salicaceae) in a heterogeneous landscape. American Journal of Botany 79:728-736.

Kay, C. E. 1993. Aspen seedlings in recently burned areas of Grand Teton and Yellowstone National Parks. Northwest Science 67:94104.

McDonough, W. T. 1985. Sexual reproduction, seeds and seedlings. Pages 25-33, in: DeByle, N. V., and R. P. Winokur, Aspen ecology and management in the western United States. USDA General Technical Report RM-119.

Pearson, G. A. 1914. The role of aspen in the reforestation of mountain burns in Arizona and New Mexico. Plant World 17:249-260.

Romme, W. H., and M. G. Turner. 1991. Implications of global climate change for biogeographic patterns in the Greater Yellowstone Ecosystem. Conservation Biology 5:373386.

Romme, W. H., M. G. Turner, R. H. Gardner, W. W. Hargrove, G. A. Tuskan, D. G. Despain, and R. A. Renkin. 1997. A rare episode of sexual reproduction in aspen (Populus tremuloides) following the 1988 Yellowstone fires. Natural Areas Journal 17:17-25. 